\title{
Consequences of Supraphysiological Dialysate Magnesium on Arterial Stiffness, Hemodynamic Profile, and Endothelial Function in Hemodialysis: A Randomized Crossover Study Followed by a Non- Controlled Follow-Up Phase
}

\author{
Rosaria Del Giorno (D) - Soraya Lavorato Hadjeres · Kevyn Stefanelli • \\ Giampiero Allegra • Claudia Zapparoli · Lazarevic Predrag • \\ Lorenzo Berwert · Luca Gabutti \\ Received: August 18, 2020 / Accepted: September 12, 2020 / Published online: September 29, 2020 \\ (C) The Author(s) 2020
}

\section{ABSTRACT}

Introduction: Increasing dialysate magnesium $\left(\mathrm{D}-\mathrm{Mg}^{2+}\right)$ appears to be an intriguing strategy to obtain cardiovascular benefits in subjects with end-stage kidney disease (ESKD) on hemodialysis. To date, however, hemodialysis guidelines do not suggest to increase $\mathrm{D}-\mathrm{Mg}^{2+}$ routinely set at $0.50 \mathrm{mmol} / \mathrm{L}$.

Rosaria Del Giorno and Soraya Lavorato Hadjeres are joint first authors.

Digital Features To view digital features for this article go to https://doi.org/10.6084/m9.figshare.12943172.

R. Del Giorno $(\varangle) \cdot$ G. Allegra · C. Zapparoli ·

L. Gabutti ( $\square)$

Department of Internal Medicine, Clinical Research Unit, Regional Hospital of Bellinzona and Valli, Ente Ospedaliero Cantonale, Bellinzona, Switzerland e-mail: rosaria.delgiorno@eoc.chL. Gabutti

e-mail: luca.gabutti@eoc.ch

S. Lavorato Hadjeres · L. Predrag · L. Berwert .

L. Gabutti

Nephrology and Dialysis Service, Regional Hospital of Bellinzona and Valli, Ente Ospedaliero

Cantonale, Bellinzona, Switzerland

K. Stefanelli

Department of Social Sciences and Economics,

Sapienza University of Rome, Rome, Italy

R. Del Giorno - L. Gabutti

Institute of Biomedicine, University of Southern

Switzerland, Lugano, Switzerland
Methods: A randomized 4-week crossover study aimed at investigating the consequences of increasing $\mathrm{D}-\mathrm{Mg}^{2+}$ from 0.50 to $0.75 \mathrm{mmol} / \mathrm{L}$ on arterial stiffness, hemodynamic profile, and endothelial function in subjects undergoing hemodialysis. The long-term effect of higher ${\mathrm{D}-\mathrm{Mg}^{2+}}^{2+}$ mineral metabolism markers was investigated in a 6-month follow-up. Data were analyzed by linear mixed models for repeated measures.

Results: Data of 39 patients were analyzed. Pulse wave velocity and pulse pressure significantly decreased on the higher $\mathrm{D}-\mathrm{Mg}^{2+}$ compared with the standard one by $-0.91 \mathrm{~m} / \mathrm{s}(95 \%$ confidence interval -1.52 to $-0.29 ; p=0.01$ ) and $-9.61 \mathrm{mmHg}(-18.89$ to $-0.33, p=0.04)$, respectively. A significant reduction in systolic blood pressure of $-12.96 \mathrm{mmHg}(-24.71$ to $-1.22, p=0.03$ ) was also observed. No period or carryover effects were observed. During the long-term follow-up phase the higher $\mathrm{D}-\mathrm{Mg}^{2+}$ significantly increased ionized and total serum $\mathrm{Mg}$ (respectively from 0.54 to 0.64 and from 0.84 to $1.07 \mathrm{mmol} / \mathrm{L}$; mean percentage change from baseline to follow-up $+21 \%$ and $+27 \%$; $p \leq 0.001)$ while parathormone (PTH) decreased significantly (from 36.6 to 34.4 pmol/ L; \% change $-11 \%, p=0.03)$.

Conclusions: Increasing dialysate magnesium improves vascular stiffness in subjects undergoing maintenance hemodialysis. The present findings merit a larger trial to evaluate the 
effects of $0.75 \mathrm{mmol} / \mathrm{L} \mathrm{D}^{-\mathrm{Mg}^{2+}}$ on major clinical outcomes.

Trial Registration: The study was retrospectively registered on the ISRCTN registry (ISRCTN 74139255) on 18 June 2020.

Keywords: Arterial stiffness; Blood pressure; Dialysate magnesium; Pulse wave velocity; Vascular endothelial function

\section{Key Summary Points}

Why carry out this study?

Cardiovascular diseases represent a leading cause of mortality in patients with endstage kidney disease.

Arterial calcifications, hypertension, and increased arterial stiffness are the bestunderstood factors involved in the genesis of cardiovascular disease in patients undergoing hemodialysis.

Increasing dialysate magnesium concentration represents an intriguing potential strategy to obtain cardiovascular benefits in patients undergoing hemodialysis.

\section{What was learned from the study?}

Increasing dialysate magnesium concentration from 0.50 to $0.75 \mathrm{mmol} / \mathrm{L}$ could lead to a benefit in terms of arterial stiffness in the absence of significant adverse hemodynamic events and of unfavorable consequences on bone metabolism.

Increasing magnesium in dialysate represents a captivating therapeutic option in patients undergoing hemodialysis; however, the optimal dialysate magnesium concentration and the best strategy to tailor the dialysate both remain unknown.

Considering the high inter-individual variability of serum magnesium, the best option would be to personalize the dialysate prescription.

\section{DIGITAL FEATURES}

This article is published with digital features to facilitate understanding of the article. To view digital features for this article go to https://doi. org/10.6084/m9.figshare.12943172.

\section{INTRODUCTION}

Cardiovascular diseases (CV) represent a leading cause of mortality in patients with end-stage kidney disease (ESKD), accounting for nearly $50 \%$ of all deaths [1]. The severity of cardiovascular injury in these patients is the consequence of a complex and multifactorial vascular health impairment, in which several factors are involved. Artery calcifications, higher prevalence of hypertension with chronic stress on the vascular wall and increased arterial stiffness are the best-understood factors involved in the promotion of $\mathrm{CV}$ disease in patients undergoing hemodialysis (HD) [2-4]. In addition in ESKD, endothelial dysfunction plays an important role in atherogenesis, representing an early predictive marker of cardiovascular outcome [5].

In recent years the positive role of magnesium $(\mathrm{Mg})$ has been highlighted in terms of cardiovascular benefits in patients with ESKD. Experimental in vitro and in vivo models have shown that in chronic kidney disease (CKD) higher levels of $\mathrm{Mg}$ could up-regulate the osteoblastic gene expression, block smooth vascular muscle cell transdifferentiation, and prevent increased stiffness and calcification processes [6-13].

Results of interventional studies have demonstrated the role of $\mathrm{Mg}$ in improving endothelial cell dysfunction, whilst conversely $\mathrm{Mg}$ deficiency represents a trigger for vascular constriction, platelet aggregation, inflammation, and oxidative stress, resulting in endothelial cell dysfunction and vascular calcification [14-16].

Moreover, it was demonstrated that increasing dialysate magnesium (D- $\mathrm{Mg}^{2+}$ ) concentration during HD sessions could improve the hemodynamic profile, preventing the occurrence of intradialytic hypotension (IDH). 
The potential anti-atherosclerotic, hemodynamic, and endothelial preservation benefits which could result from increasing $\mathrm{Mg}$ in dialysate thus appear intriguing, even more so considering the previously found relevant rate (around 11\%) of pre- and post-HD hypomagnesemia in patients dialyzed with a $\mathrm{Mg}$ concentration of $0.50 \mathrm{mmol} / \mathrm{L}$ [17].

More recently, findings of a randomized controlled trial have shown a functional improvement in mineral buffering, showing a change in global serum calcification assay T50, which indicates a higher potency of the serum to inhibit calcification after increasing standard $\mathrm{D}-\mathrm{Mg}^{2+}$ from 0.50 to $1.00 \mathrm{mmol} / \mathrm{L}$ for 4 weeks [18].

Considering all the aforementioned positive effects, increasing D- $\mathrm{Mg}^{2+}$ appears to be a simple, inexpensive, and effective way to obtain an overall CV benefit. However, to date, HD guidelines do not suggest to increase the $\mathrm{D}-\mathrm{Mg}^{2+}$, routinely set at $0.50 \mathrm{mmol} / \mathrm{L}$. Despite the potential beneficial effects of increasing $\mathrm{Mg}$ levels, hypermagnesemia could cause several side effects including electrocardiographic, neuronal, and bone metabolism abnormalities [19]. It is important to note that the real incidence of hypermagnesemia could be underestimated in patients on HD. Previous studies on the topic assessed only the total serum magnesium (tot-Mg), i.e., the biologically active ionized fraction plus the part bound to proteins or complexed with anions; the ionized part (ion$\mathrm{Mg}^{2+}$ ) is influenced by the fluctuations in albuminemia, as well as electrolyte and acid-base disturbances seen in hemodialysis. As a result, tot-Mg has two major limitations: it does not adequately reflect either the active magnesium pool or the total body content; the extracellular magnesium represents only $1 \%$ of the body magnesium. In a previous study in a population of patients on chronic HD we found that ion- $\mathrm{Mg}^{2+}$ could be useful in unmasking hypo- and hypermagnesemia otherwise not detectable by assessing only the tot-Mg [17].

To study the vascular effect of increasing magnesium in dialysate, we designed a randomized, crossover study in which we tested whether increasing $\mathrm{D}-\mathrm{Mg}^{2+}$ from 0.50 to $0.75 \mathrm{mmol} / \mathrm{L}$ could affect arterial stiffness, the hemodynamic profile, and the endothelial function in patients with ESKD on hemodialysis. We also aimed to investigate in a follow-up period of 6 months the long-term effect of increased magnesium in dialysate on mineral metabolism markers and the utility of ion $-\mathrm{Mg}^{2+}$ assessment.

\section{METHODS}

\section{Study Design}

The study was a randomized two-period treatment crossover with long-term follow-up conducted between September 2018 and July 2019 in the dialysis unit of the teaching Hospital of Bellinzona and Valli, Bellinzona, Switzerland. After enrollment (phase 0, visit 0), the patients were randomly assigned to a 2-week treatment (six HD sessions) with either standard $\mathrm{D}-\mathrm{Mg}^{2+}$ (group 1, D-Mg ${ }^{2+} 0.50 \mathrm{mmol} / \mathrm{L}$ treatment) or high $\mathrm{D}_{-\mathrm{Mg}^{2+}}$ (group 2, D-Mg ${ }^{2+} 0.75 \mathrm{mmol} / \mathrm{L}$ treatment), and a second 2-week crossover phase (a further six HD sessions, phase 2), using a random numbers list. The standard calcium dialysate concentration in use was $1.25 \mathrm{mmol} /$ L. Neither the nephrologist nor the patient was blind to the assigned treatment. For details of the experimental design, see Fig. 1.

After the 4 weeks of crossover, subjects did not come back to the original $\mathrm{D}-\mathrm{Mg}^{2+}$ concentration, continuing dialysis with $\mathrm{D}-\mathrm{Mg}^{2+}$ set at $0.75 \mathrm{mmol} / \mathrm{L}$ as already planned for every patient by the internal guidelines of the network to whom the dialysis center of the study belongs. Patients were thus followed for a further 6 months to assess any long-term metabolic changes related to the increased $\mathrm{D}-\mathrm{Mg}^{2+}$ concentration (follow-up phase). Comorbidities and medications were recorded at baseline; clinical and laboratory measurements were recorded at baseline, at each HD session of the crossover, and monthly in the follow-up.

\section{Study Participants}

All patients undergoing regular HD treatment at the dialysis center of the Regional Hospital of 


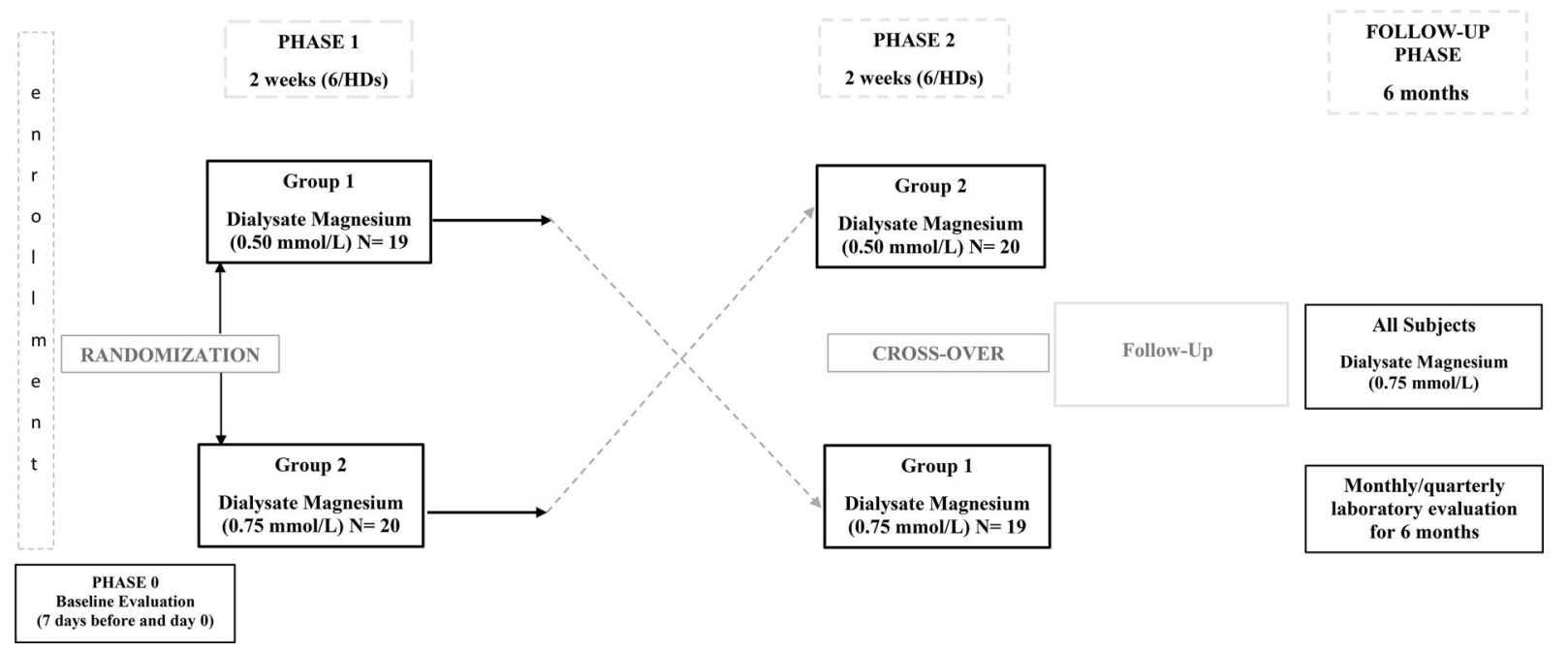

Fig. 1 Experimental design: randomized two-period treatment crossover trial and long-term follow-up

Bellinzona and Valli were screened (40 subjects), and the participation in the study in conjunction with their regular HD sessions was proposed to all those eligible. Inclusion criteria were at least 18 years of age; treatment in-center with maintenance HD for at least 3 months; ability to understand the protocol and to give written informed consent. Exclusion criteria were acute illness requiring hospitalization and pregnancy or potential for pregnancy. Thirtynine patients completed the crossover. During the follow-up period ( $\left.\mathrm{D}-\mathrm{Mg}^{2+} 0.75 \mathrm{mmo} / \mathrm{L}\right)$, five patients withdrew (four died, one changed hemodialysis center) and data of 34 patients were analyzed (see Fig. 2, flowchart of the study population). The study adhered to the principles of the Declaration of Helsinki and was approved by the SwissEthics Commission (comitato etico canton Ticino, ID number CE $3358,2018)$. All study participants gave written informed consent. All procedures performed in studies involving humanparticipants were in accordance with the ethical standards and with the 1964 Helsinki declaration and its later amendments or comparable ethical standards. The study was retrospectivelyregistered on the ISRCTN registry (ISRCTN 74139255) on June 18, 2020. All participants signed an informed consent document.

\section{Outcomes}

Primary outcomes were changes between the two treatment groups in (i) vascular stiffness as estimated by pulse wave velocity (PWV), augmentation index (AI), and pulse pressure (PP). Secondary outcomes were changes between treatment groups in (i) hemodynamic profile, as measured by systolic and diastolic blood pressure (SBP and DBP), mean blood pressure (MAP), and heart rate (HR); (ii) endothelial functions, as measured by reactive hyperemia index (RHI); (iii) no significant worsening in events related to hemodynamics (i.e., IDH and bradycardia); and (iv) no significant increase during the 4-week crossover phase in pre/postdialytic incidence of hypermagnesemia or hyper/ hypocalcemia.

Intradialytic hypotension (IDH) was defined as a decrease in systolic blood pressure of at least $20 \mathrm{mmHg}$ or a decrease in mean arterial pressure (MAP) of at least $10 \mathrm{mmHg}[20,21]$. Considering that a threshold-based definition of IDH (systolic $\mathrm{BP}<100 \mathrm{mmHg}$ ) may falsely identify IDH where changes in BP do not, we adopted only decline-based criteria: intradialytic bradycardia as a heart rate no greater than 50 beats/min; hypermagnesemia and clinically relevant hypermagnesemia as a serum ionized magnesium of at least 0.65 and at least 


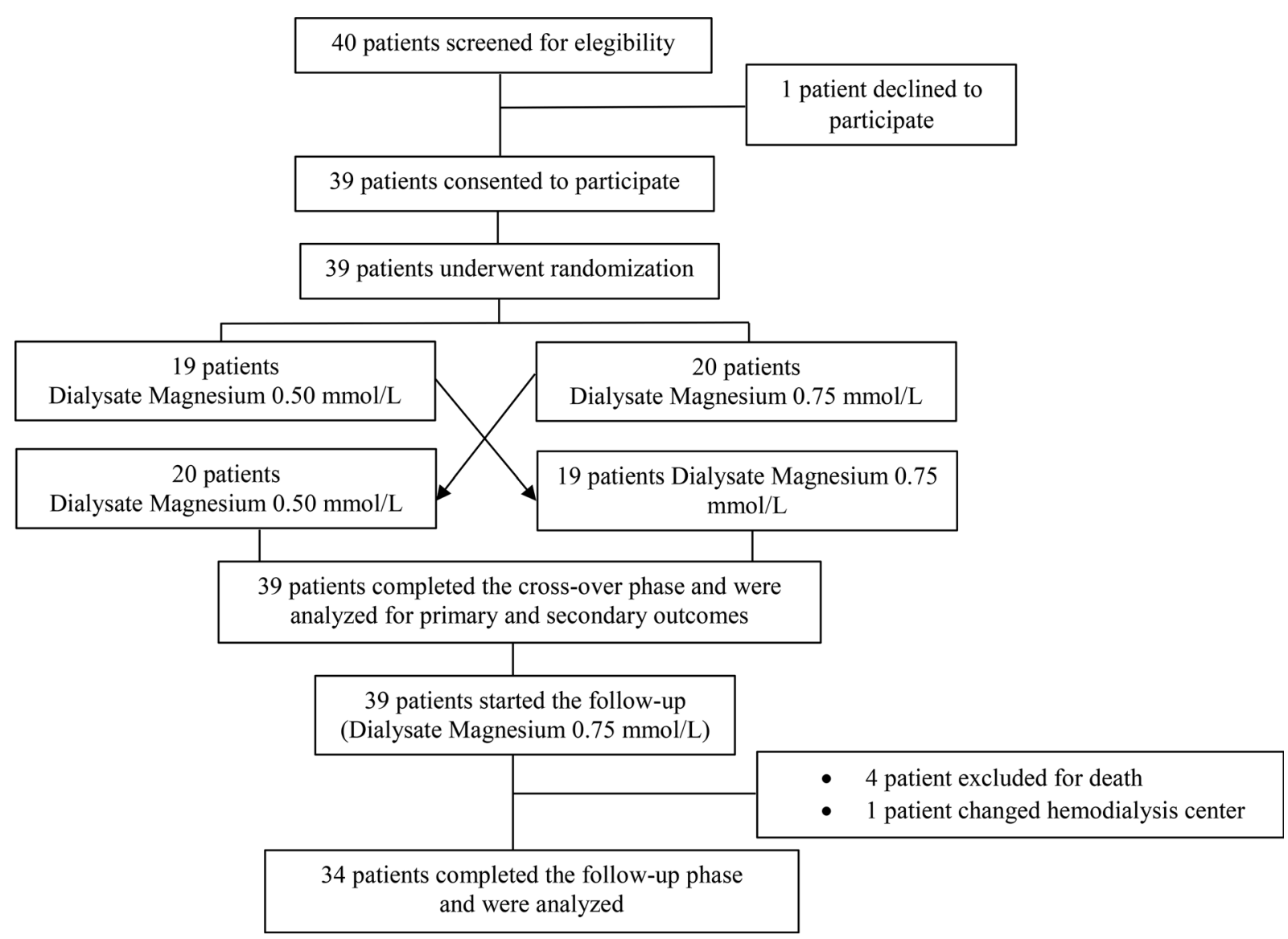

Fig. 2 Flowchart of the study population, including the number of patients who were screened, gave consent, underwent randomization, completed the crossover phase, and were analyzed for the long-term follow-up phase

$0.81 \mathrm{mmol} / \mathrm{L}$, respectively; hypercalcemia as a serum ionized calcium of least $1.21 \mathrm{mmol} / \mathrm{L}$; hypocalcemia as a serum ionized calcium no greater than $1.14 \mathrm{mmol} / \mathrm{L}$. During the longterm, 6-month follow-up phase (D-Mg ${ }^{2+}$ $0.75 \mathrm{mmol} / \mathrm{L}$ ), changes in the following markers of mineral and bone metabolism were investigated: ionized calcium, intact parathyroid hormone (PTH), 25-OH-vitamin D, ionized magnesium, and total magnesium levels.

\section{Vascular Stiffness, Hemodynamic Profile, Endothelial Function, and Laboratory Parameters}

PWV, AI, and PP were studied as markers of vascular stiffness. An oscillometric device (Mobil-O-Graph, IEM, Stolberg, Germany) was used that simultaneously provided a blood pressure measurement and, via a generalized transfer function, estimated PWV and AI (AIT Austrian Institute of Technology GmbH, Vienna, Austria) [22].

The Mobil-O-Graph is a noninvasive, oscillometric, non-operator-dependent device for the assessment of arterial stiffness based on a conventional brachial cuff for adults with an integrated high-fidelity pressure sensor. The device firstly records a brachial oscillometric BP measurement and afterward a brachial pulse waveform. Using an integrated ARCSolver pulse wave analysis algorithm (AIT Austrian Institute of Technology $\mathrm{GmbH}$, Vienna, Austria), data derived from pulse wave analysis are integrated into a mathematical model deriving PWV values. The reliability of arterial stiffness estimates provided by Mobil-O-Graph was previously assessed against invasive and noninvasive 
validated measurement methods, in several populations as well as in patients on HD [23-25]. In a previous comparison study, it was shown that estimates of AI and PWV provided by Mobil-O-Graph were not significantly different from those obtained by SphygmoCor (ArtCor, Sydney, Australia) [26], the most used method for noninvasive assessment of vascular stiffness. Following a standardized procedure, arterial stiffness was estimated during the crossover phase for each patient at each HD session thrice (at the beginning, after half of the time, and at the end) to afford a total of 36 measurements for each parameter per patient.

An appropriately sized blood pressure cuff was firstly attached to the participant's nonfistula arm in a sitting position and afterwards blood pressure (BP), PWV, AI, and PP were acquired. Measurements were not immediately available during the procedure, but downloaded into the computer at the end of each HD session. All measurements were performed by the same trained physician even though the procedure is not operator dependent. Brachial artery $\mathrm{BP}$ was measured following a standardized procedure for all patients and for all HD sessions. The following hemodynamic parameters were also collected: systolic blood pressure (SBP), diastolic blood pressure (DBP), mean arterial pressure (MAP), heart rate (HR), and PP. MAP and PP were calculated from peripheral SBP and DBP using the following formulae: $\mathrm{MAP}=$ $\mathrm{DBP}+0.4(\mathrm{SBP}-\mathrm{DBP})$ and $\mathrm{PP}=\mathrm{SBP}-\mathrm{DBP}$. As recommended by the National Kidney Foundation KDOQI guidelines, BPs were acquired with patients in a resting and seated position. Measurements were obtained immediately before starting, after half of the time, and at the end of each dialysis session. All BP values during the experimental phase (three measurements for each HD session, i.e., 18 per patient and per treatment phase) were averaged.

During the crossover, at each HD session, the following laboratory parameters were collected pre and post HD (24 measurements for each parameter): ionized magnesium (ion- $\mathrm{Mg}^{2+}$, normal range $0.45-0.65 \mathrm{mmol} / \mathrm{L}$ ), ionized calcium (normal range, $1.15-1.31 \mathrm{mmol} / \mathrm{L}$ ), and $\mathrm{pH}$, using an ionometer (Microlyte 6 Analyzer, Kone Instruments, Espoo, Finland). The decision to investigate a magnesium dialysate concentration of $0.75 \mathrm{mmol} / \mathrm{L}$ was made on the basis of the standard dialysis fluids routinely available in Switzerland. A concentration of $0.65 \mathrm{mmol} / \mathrm{L}$ would have been closer to the physiologic values, but that choice would have required the production of an ad hoc dialysis concentrate, limiting the reliability of the results in real-world hemodialysis.

Blood samples were collected following a standardized procedure. Blood withdrawals were performed within $10 \mathrm{~min}$ from the starting and ending of each HD session. A trained designated nurse was responsible for the prompt analysis of the blood samples within $15 \mathrm{~min}$ from their execution using an ionometer (Microlyte 6 Analyzer, Kone Instruments, Espoo, Finland) located in the same dialysis unit. The ionometer was monitored daily for quality by a designated laboratory technician and checked for calibration before using.

In order to investigate the impact of increasing $\mathrm{D}-\mathrm{Mg}^{2+}$ on endothelial functions, a validated, non-operator-dependent device for noninvasive measurement of endothelial function was used, EndoPAT 2000 (Itamar Medical Inc., Israel). Placed on a fingertip, the device was able to measure arterial pulse volume changes induced by upper arm cuff occlusion, thus generating the reactive hyperemia index (RHI) automatically [26, 27]. RHI was measured at the end of each one of the 2 weeks of the crossover phases. After the crossover, following the implementation of a new guideline of the network to whom the dialysis unit belongs, each participant underwent $\mathrm{HD}$ with $\mathrm{D}-\mathrm{Mg}^{2+}$ set at $0.75 \mathrm{mmol} / \mathrm{L}$. During a 6-month followup period, ion- $\mathrm{Mg}^{2+}$, ionized calcium, tot- $\mathrm{Mg}^{2+}$, albumin (normal range 35-52 g/L), bicarbonate $\left(\mathrm{HCO}_{3}{ }^{-}, \mathrm{mmol} / \mathrm{L}\right)$, phosphate $\left(\mathrm{PO}_{4}{ }^{3-}\right.$, normal range $0.81-1.42 \mathrm{mmol} / \mathrm{L})$, and potassium $\left(\mathrm{K}^{+}\right.$, 3.5-5.1 mmol/L) were tested once a month; and parathormone (PTH, normal range 1.6-$6.9 \mathrm{pmol} / \mathrm{L}$ ) and 25-OH-vitamin D (normal values $>20 \mathrm{ng} / \mathrm{ml}$ ) once every 3 months.

The standardized procedures for laboratory analysis described above were also applied during the follow-up phase except for PTH and vitamin $\mathrm{D}$, which were performed once every 3 months as a pre-HD blood withdrawal and 
analyzed by the central laboratory of the hospital. All blood tests were determined in the same laboratory.

\section{Statistical Analyses}

Given the pilot nature of this study the sample size of 35 patients was primarily based on feasibility considerations. Demographic, laboratory, and clinical characteristics at baseline were summarized and stratified by the order of the intervention received $\left(\mathrm{D}-\mathrm{Mg}^{2+} 0.50\right.$ and then $0.75 \mathrm{mmol} / \mathrm{L}$ vs. 0.75 and then $0.50 \mathrm{mmol} / \mathrm{L}$ ). Continuous variables are presented as mean and standard deviation (SD). Tests for the fixed effects of treatment, period, and sequence were performed using linear mixed models with a random intercept for each subject. Equality of variance in the two groups and normality of residual errors were checked. The carryover effect was assessed using the Wilcoxon signed rank test and the exact Wilcoxon rank sum test.

Adverse events were compared between the $\mathrm{D}-\mathrm{Mg}^{2+}$ treatment groups by relative risk (RR), and in order to take into account the crossover design, odds ratios (ORs) obtained by logistic regression (with random effects) were also calculated.

Long-term effects of increasing $\mathrm{D}^{-\mathrm{Mg}^{2+}}$ on markers of mineral metabolism and on magnesium levels were investigated considering the changes from baseline to follow-up for each one of the parameters and comparing between treatments and follow-up vs. baseline with paired $t$ tests. Changes over time for tot-Mg, ion- $\mathrm{Mg}^{2+}, \mathrm{PO}_{4}{ }^{3-}$, calcium, $\mathrm{PTH}$, and 25-OH-vitamin $\mathrm{D}$ were analyzed using linear mixed models considering time as the repeated measure. As a result of skewed distributions, PTH and 25-OH-vitamin D were log-transformed in the models. To ease interpretation, results were back-transformed. Data analysis was performed using $\mathrm{R}$ statistical software (https://www.rproject.org).

\section{RESULTS}

\section{Patients}

Figure 2 displays the flow diagram of the study. Of the 40 patients screened for eligibility, 39 underwent randomization, completed the crossover phase, and were analyzed for primary and secondary outcomes. During the 6-month follow-up phase $\left(\mathrm{D}-\mathrm{Mg}^{2+} 0.75 \mathrm{mmol} / \mathrm{L}\right)$, four patients died and one patient changed dialysis center, resulting in a sample of 34 patients analyzed. Figure 1 depicts the study design and patient randomization. Patient characteristics at enrollment by treatment group are displayed in Table 1. Characteristics were representative of a typical Swiss HD cohort: the most prevalent causes of ESRD were hypertension (41\%) and diabetes (33\%), and the mean age was $76.6 \pm 11.4$ years. The following hemodynamic and arterial stiffness parameters (mean \pm SD) were observed at baseline: SBP $126.4 \pm 21.1 \mathrm{mmHg} ;$ DBP $71.0 \pm 13.8 \mathrm{mmHg}$; heart rate $66.0 \pm 10.1 \mathrm{bpm}$; PWV $11.3 \pm 1.9 \mathrm{~m} /$ $\mathrm{s} ;$ and augmentation index $27.3 \pm 12.3 \%$. Patients showed a normomagnesemic and normocalcemic pattern at baseline with respectively $0.54 \pm 0.07$ and $1.13 \pm 0.10 \mathrm{mmol} / \mathrm{L}$; six patients were treated with magnesium supplements (three in each group based on starting $\left.\mathrm{D}-\mathrm{Mg}^{2+}\right)$. No significant modifications of the usual medication and of the remaining dialysis prescriptions were made during the study.

\section{Primary Outcomes: Effect of Increasing Dialysate Magnesium on Arterial Stiffness, Hemodynamic Patterns, and Endothelial Functions}

During the $\mathrm{D}-\mathrm{Mg}^{2+} 0.75 \mathrm{mmol} / \mathrm{L}$ treatment, subjects showed an average decrease (95\% confidence interval) compared with $\mathrm{D}-\mathrm{Mg}^{2+}$ $0.50 \mathrm{mmol} / \mathrm{L}$ treatment of pulse wave velocity of $-0.91 \mathrm{~m} / \mathrm{s}(-1.52$ to $-0.29 ; p=0.014$; absolute values for $\mathrm{D}-\mathrm{Mg}^{2+}$ of $0.75 \mathrm{mmol} / \mathrm{L}$ and $0.50 \mathrm{mmol} / \mathrm{L}, 11.2$ and $10.3 \mathrm{~m} / \mathrm{s}$ ) and of pulse pressure of $-9.61 \mathrm{mmHg}$ ( -18.89 to -0.33 ; $p=0.04 ;$ absolute values for $\mathrm{D}^{-\mathrm{Mg}^{2+}}$ of $0.75 \mathrm{mmol} / \mathrm{L}$ and $0.50 \mathrm{mmol} / \mathrm{L}, \quad 43.9$ and 
Table 1 Baseline descriptive statistics by treatment groups

Variables Whole study sample $(n=39)$
Dialysate magnesium

Start 0.50 then $0.75 \mathrm{mmol} / \mathrm{L}$ Start 0.75 then $0.50 \mathrm{mmol} / \mathrm{L}$ (n.20)

(n.19)

$15 / 4(79 / 21)$

$15 / 5(75 / 25)$

$74.4 \pm 14.5$

$78.9 \pm 6.2$

$28.9 \pm 5.4$

$26.8 \pm 5.9$

$6(30)$

7 (36.8)

7 (35)

$9(47.4)$

4 (20)

0

$1(5)$

$3(15.8)$

2 (10)

0

Hemodynamic parameters

\begin{tabular}{|c|c|c|c|}
\hline $\mathrm{SBP}, \mathrm{mmHg}$ & $126.4 \pm 21.1$ & $131.1 \pm 18.7$ & $121.6 \pm 22.9$ \\
\hline $\mathrm{DBP}, \mathrm{mmHg}$ & $71.0 \pm 13.8$ & $67.9 \pm 10.9$ & $73.9 \pm 15.9$ \\
\hline Heart rate, beats/min & $66.0 \pm 10.1$ & $69.2 \pm 12.4$ & $62.7 \pm 5.3$ \\
\hline $\mathrm{MAP}, \mathrm{mmHg}$ & $96.4 \pm 15.6$ & $100.1 \pm 15.6$ & $92.5 \pm 14.9$ \\
\hline Pulse pressure, $\mathrm{mmHg}$ & $55.4 \pm 16.0$ & $57.1 \pm 14.3$ & $53.7 \pm 17.8$ \\
\hline Augmentation index, \% & $27.3 \pm 12.3$ & $26.9 \pm 10.5$ & $27.6 \pm 14.4$ \\
\hline $\mathrm{PWV}, \mathrm{m} / \mathrm{s}$ & $11.3 \pm 1.9$ & $11.2 \pm 2.1$ & $11.3 \pm 1.7$ \\
\hline \multicolumn{4}{|l|}{ Laboratory measurements } \\
\hline Creatinin, $\mu \mathrm{mol} / \mathrm{L}$ & $686.3 \pm 177.5$ & $683.3 \pm 200.1$ & $689.5 \pm 155.9$ \\
\hline $\mathrm{BUN}, \mathrm{mmol} / \mathrm{L}$ & $24.4 \pm 6.9$ & $24.2 \pm 7.8$ & $24.5 \pm 6.2$ \\
\hline Phosphate, mmol/L & $1.49 \pm 0.47$ & $1.49 \pm 0.53$ & $1.50 \pm 0.40$ \\
\hline Albumin, g/L & $40.2 \pm 4.3$ & $40.3 \pm 4.1$ & $40.2 \pm 4.7$ \\
\hline PTH, pmol/L & $36.8 \pm 0.98$ & $37.4 \pm 20.0$ & $36.2 \pm 24.6$ \\
\hline $\begin{array}{l}\text { 25-OH-vitamin D, ng/ } \\
\mathrm{mL}\end{array}$ & $30.3 \pm 17.6$ & $30.5 \pm 20.3$ & $30.2 \pm 14.8$ \\
\hline $\mathrm{pH}\left(\mathrm{H}^{+}\right)$ & $7.34 \pm 0.05$ & $7.32 \pm 0.05$ & $7.36 \pm 0.031$ \\
\hline Ion- $\mathrm{Ca}^{2+}, \mathrm{mmol} / \mathrm{L}$ & $1.13 \pm 0.10$ & $1.11 \pm 0.11$ & $1.15 \pm 0.07$ \\
\hline Ion- $\mathrm{Mg}^{2+}, \mathrm{mmol} / \mathrm{L}$ & $0.54 \pm 0.07$ & $0.51 \pm 0.08$ & $0.56 \pm 0.06$ \\
\hline Potassium, mmol/L & $5.00 \pm 0.78$ & $5.01 \pm 0.70$ & $5.00 \pm 0.88$ \\
\hline
\end{tabular}


Table 1 continued

\begin{tabular}{|c|c|c|c|}
\hline \multirow[t]{2}{*}{ Variables } & \multirow{2}{*}{$\begin{array}{l}\text { Whole study sample } \\
(n=39)\end{array}$} & \multicolumn{2}{|l|}{ Dialysate magnesium } \\
\hline & & $\begin{array}{l}\text { Start } 0.50 \text { then } 0.75 \mathrm{mmol} / \mathrm{L} \\
(\mathrm{n} .20)\end{array}$ & $\begin{array}{l}\text { Start } 0.75 \text { then } 0.50 \mathrm{mmol} / \mathrm{L} \\
(\mathrm{n} .19)\end{array}$ \\
\hline Ultrafiltered volume, $\mathrm{mL}$ & $2042.8 \pm 1041.02$ & $1902.7 \pm 1090.0$ & $2220.4 \pm 983.1$ \\
\hline \multicolumn{4}{|l|}{ Comorbidities (\%) } \\
\hline $\begin{array}{l}\text { Diabetes mellitus type } 1 \\
\text { and } 2\end{array}$ & $17(44)$ & $7(35)$ & $10(53)$ \\
\hline Hypertension & $21(54)$ & $10(50)$ & $11(57)$ \\
\hline Hypercholesterolemia & $24(63)$ & $10(53)$ & $14(74)$ \\
\hline Cancer & $10(25)$ & $6(30)$ & $4(21)$ \\
\hline Gastointestinal disorders & $9(23)$ & $6(30)$ & $3(16)$ \\
\hline
\end{tabular}

$53.6 \mathrm{mmHg}$ ). Concerning the hemodynamic profile a significant reduction in systolic blood pressure of $-12.96 \mathrm{mmHg}$ ( -24.71 to -1.22 , $p=0.032$ ) was observed with the $\mathrm{D}-\mathrm{Mg}^{2+}$ $0.75 \mathrm{mmol} / \mathrm{L}$ treatment compared with $\mathrm{D}-\mathrm{Mg}^{2+}$ $0.50 \mathrm{mmol} / \mathrm{L}$ treatment (absolute values for $\mathrm{D}^{-\mathrm{Mg}^{2+}}$ of $0.75 \mathrm{mmol} / \mathrm{L}$ and $0.50 \mathrm{mmol} / \mathrm{L}$, 112.8 and $125.8 \mathrm{mmHg}$ ). A concurrent reduction in mean blood pressure of $-7.15 \mathrm{mmHg}$ ( -15.14 to $0.83, p=0.081$; absolute values for $\mathrm{D}-\mathrm{Mg}^{2+} 0.75 \mathrm{mmol} / \mathrm{L}$ and $0.50 \mathrm{mmol} / \mathrm{L}, 89.3$ and $96.4 \mathrm{mmHg}$ ) was found even if not significant. During the crossover phase no significant changes in the other hemodynamic parameters were observed (heart rate, diastolic blood pressure), nor in laboratory tests (total magnesium, ionized magnesium, ionized calcium) and augmentation index. No periods or carryover effects were observed. A trend towards an endothelial function improvement of +0.15 $(-0.35-0.65, p=0.107)$ during the $\mathrm{D}-\mathrm{Mg}^{2+}$ $0.75 \mathrm{mmol} / \mathrm{L}$ treatment was also observed even if not statistically significant Figure 3 displays results for markers of vascular stiffness, hemodynamic profile, and endothelial function parameters for subgroups. Values are shown on adapted scales, while results are reported on original scales.

\section{Secondary Outcomes}

During the intervention no statistically significant differences were observed in incidence of adverse events between $\mathrm{D}-\mathrm{Mg}^{2+} 0.75 \mathrm{mmol} / \mathrm{L}$ treatment vs. $\mathrm{D}-\mathrm{Mg}^{2+} 0.50 \mathrm{mmol} / \mathrm{L}$ treatment (Table 2). The relative risk for IDH was not significantly higher in the $\mathrm{D}-\mathrm{Mg}^{2+} 0.75 \mathrm{mmol} / \mathrm{L}$ treatment vs. $\mathrm{D}-\mathrm{Mg}^{2+} 0.50 \mathrm{mmol} / \mathrm{L}$ treatment: RR 1.10 (95\% CI 0.90-1.34); this was also the case for intradialytic bradycardia, RR 2.0 (95\% CI 0.66-6.10), and for hypo/hypercalcemia, respectively RR 1.03 (95\% CI $0.89-1.18)$ and 1.13 (95\% CI 0.66-1.93). The occurrence of predialytic hypermagnesemia was higher during the $\mathrm{D}-\mathrm{Mg}^{2+} 0.75 \mathrm{mmol} / \mathrm{L}$ treatment phase, RR 2.89 (95\% CI 1.56-5.34, $p \leq 0.001$ ). However considering only the proportion of clinically relevant hypermagnesemia (i.e., serum ionized magnesium $\geq 0.81 \mathrm{mmol} / \mathrm{L}$ ), no cases were detected in both phases.

\section{Long-Term Effect on Mineral Metabolism Markers and Serum Magnesium}

During the 6-month follow-up phase a significant increase in serum total magnesium level was observed: from a baseline average value of 


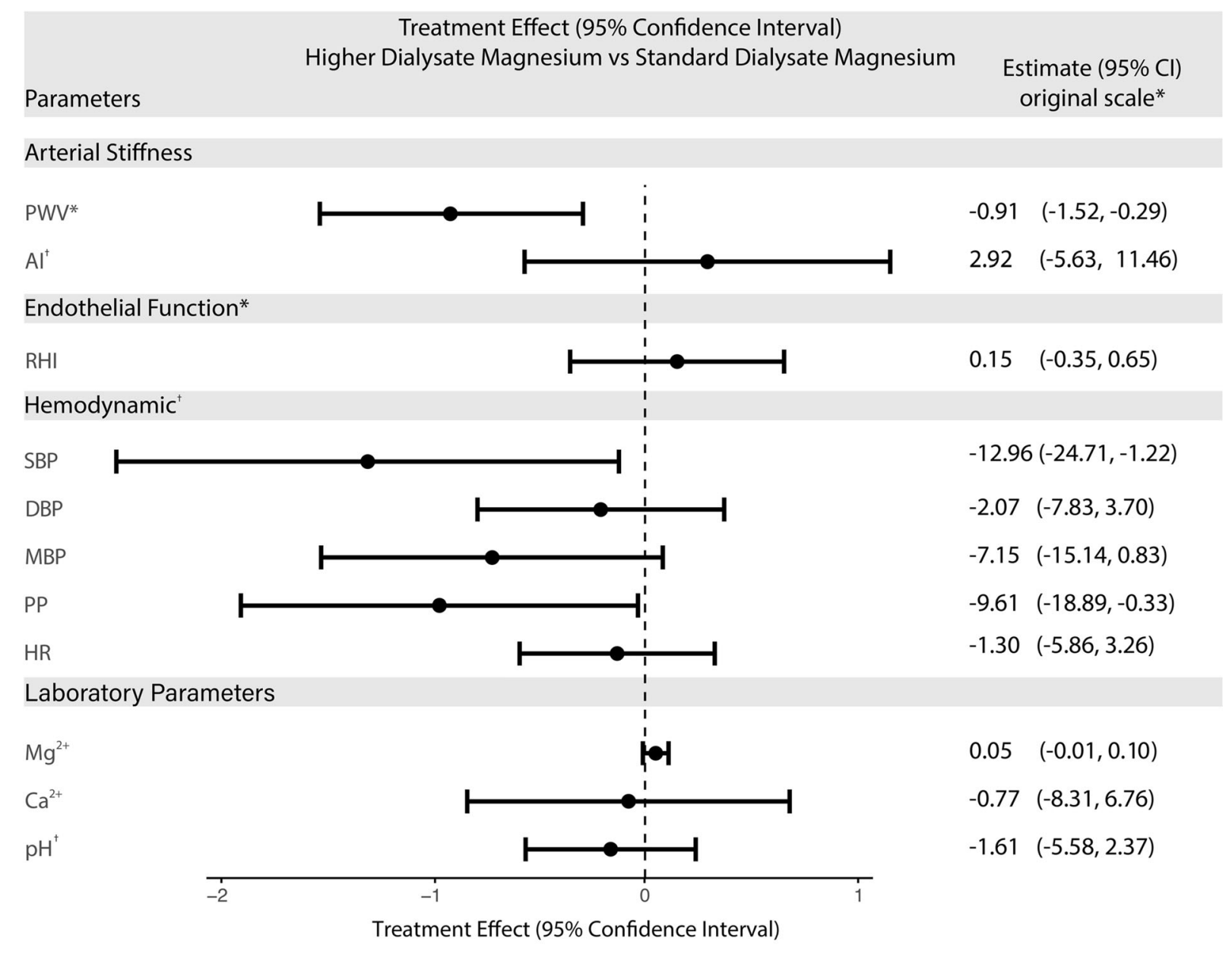

*Estimates reported on original scale

+Estimates plotted multiplied by 0.1

Fig. 3 Treatment effect. High vs. standard dialysate magnesium. Treatment effects (means and 95\% confidence intervals [95\% CI]) for markers of arterial stiffness; high $\mathrm{D}-\mathrm{Mg}^{2+}$ versus standard $\mathrm{D}-\mathrm{Mg}^{2+}$. Values are plotted on different scales (AI, SBP, DBP, PP, HR, pH multiplied by

$0.85 \pm 0.13$ to $1.06 \pm 0.13$, corresponding to a mean percentage increase from baseline to follow-up (\%, 95\% CI) of + 27\% (95\% CI 21-33), ( $p \leq 0.001$ for change over time). A similar increase was found also for whole blood ionized magnesium, which increased from a baseline average value of $0.57 \pm 0.21$ to $0.66 \pm 0.09$. A significant decrease was found for PTH, which from a baseline value of $36.6 \mathrm{pmol} / \mathrm{L}$ (95\% CI 28.8-51.9) dropped to $34.4 \mathrm{pmol} / \mathrm{L}$ (95\% CI 18.7-48.9), corresponding to a mean percentage
0.1) while results are reported on the original scale. PWV pulse wave velocity, AI augmentation index, RHI reactive hyperemia index, SBP systolic blood pressure, DBP diastolic blood pressure, MAP mean blood pressure, PP pulse pressure, HR heart rate

decrease of $-11 \%(95 \% \mathrm{CI}-22$ to 1$)(p=0.034$ for change over time). A significant increase was observed for 25-OH-vitamin D with a mean percentage change during the follow-up period of $+39 \%(95 \%$ CI $7-71)(p \leq 0.001)$. No significant changes in calcium level and in phosphorus levels were observed (Table 3). Monthly and quarterly percentage changes during follow-up for magnesium and selected mineral markers are shown in Fig. 4. 
Table 2 Adverse events for magnesium dialysates set at 0.50 and $0.75 \mathrm{mmol} / \mathrm{L}$ in the experimental crossover phase

\begin{tabular}{|c|c|c|c|c|}
\hline \multirow[t]{2}{*}{ Variable } & \multicolumn{2}{|c|}{ Dialysate magnesium } & \multirow[t]{2}{*}{ RR $(95 \% \mathrm{CI})$} & \multirow[t]{2}{*}{$p$ value } \\
\hline & $0.50 \mathrm{mmol} / \mathrm{L}$ & $0.75 \mathrm{mmol} / \mathrm{L}$ & & \\
\hline Intradialytic hypotension ${ }^{a}$ & $31(79 \%)$ & $34(89 \%)$ & $1.10(0.90-1.34)$ & 0.362 \\
\hline Intradialytic bradycardia ${ }^{\mathrm{b}}$ & $4(10 \%)$ & $8(21 \%)$ & $2.0(0.66-6.10)$ & 0.290 \\
\hline \multicolumn{5}{|l|}{ Pre-hemodialysis } \\
\hline Hypermagnesemia $^{c}$ & $9(23 \%)$ & $26(67 \%)$ & $2.89(1.56-5.34)$ & $<0.001^{*}$ \\
\hline Hypocalcemia $^{\mathrm{d}}$ & $35(89 \%)$ & $36(92 \%)$ & $1.03(0.89-1.18)$ & 0.692 \\
\hline Hypercalcemia $^{\mathrm{e}}$ & $15(38 \%)$ & $17(44 \%)$ & $1.13(0.66-1.93)$ & 0.640 \\
\hline \multicolumn{5}{|l|}{ Post-hemodialysis } \\
\hline Hypermagnesemia $^{c}$ & $3(1 \%)$ & $36(92 \%)$ & $12.0(4.03-35.73)$ & $<0.001^{*}$ \\
\hline Hypocalcemia $^{\mathrm{d}}$ & $36(92 \%)$ & $33(84 \%)$ & $0.92(0.78-1.08)$ & 0.288 \\
\hline Hypercalcemia $^{\mathrm{e}}$ & $23(59 \%)$ & $22(56 \%)$ & $0.96(0.65-1.40)$ & 0.819 \\
\hline
\end{tabular}

Values are given as number of events (percentage). Taking into account the crossover design, odds ratios (OR) were also calculated and were almost identical to RRs

$R R$ relative risk, $C I$ confidence interval, $H D$ hemodialysis

a Defined as a decrease in systolic blood pressure $\geq 20 \mathrm{mmHg}$ or a decrease in MAP, mean arterial pressure $\geq 10 \mathrm{mmHg}$

${ }^{b}$ Defined as a heart rate $\leq 50$ beats $/ \mathrm{min}$

${ }^{c}$ Defined as a serum ionized magnesium $\geq 0.65 \mathrm{mmol} / \mathrm{L}$; clinical relevant hypermagnesemia, i.e., serum ionized magnesium $\geq 0.81 \mathrm{mmol} / \mathrm{L}$ (not detected)

d Defined as a serum ionized calcium $\leq 1.14 \mathrm{mmol} / \mathrm{L}$

e Defined as a serum ionized calcium $\geq 1.21 \mathrm{mmol} / \mathrm{L}$

${ }^{*} p<0.05$

\section{DISCUSSION}

Increasing magnesium in dialysate with the aim of obtaining cardiovascular benefits represents a captivating therapeutic option in patients undergoing hemodialysis. In this randomized crossover study, we have demonstrated that increasing $\mathrm{D}-\mathrm{Mg}^{2+}$ from 0.50 to $0.75 \mathrm{mmol} / \mathrm{L}$ improves vascular stiffness in subjects undergoing maintenance hemodialysis.

Previous findings from large epidemiological studies and randomized controlled trials confirmed the hypothesis that magnesium supplementation has a protective effect on $\mathrm{CV}$ risk, suggesting arterial stiffness improvement as the underlying mechanism $[28,29]$. However, the consequences of increasing $\mathrm{D}-\mathrm{Mg}^{2+}$ on vascular stiffness and endothelial functions have not been investigated previously in patients on HD.
A pathological increase in aortic stiffness, measured as aortic pulse wave velocity, has been well demonstrated in patients with CKD and represents a strong independent predictor of survival in these patients [30]. Furthermore, arterial stiffness is considered a validated marker for cardiovascular health in patients with CKD [31]. Several pathophysiological mechanisms are considered determinants of the accelerated vascular ageing process in patients with CKD, ranging from traditional major determinants such as blood pressure to up-to-date mechanisms concerning in particular the bone-vascular axis and arterial media calcification [32].

The effect of magnesium on hemodynamic function was previously described as a multifactorial phenomenon in which magnesium exerts its vasodilatory action via a direct reduction in total peripheral resistance or a direct 
Table 3 Long-term effects of increasing dialysate magnesium on serum magnesium level and associated variables

\begin{tabular}{|c|c|c|c|c|c|}
\hline Variable & Baseline & Follow-up & $\begin{array}{l}\text { Change from } \\
\text { baseline to follow-up } \\
(95 \% \mathrm{CI})\end{array}$ & $\begin{array}{l}\text { Mean change from } \\
\text { baseline to follow-up (\%, } \\
\text { 95\% CI) }\end{array}$ & $\begin{array}{l}p \text { value for } \\
\text { difference baseline } \\
\text { vs. follow-up }\end{array}$ \\
\hline $\begin{array}{l}\text { Ion- } \mathrm{Mg}^{2+} \\
\mathrm{mmol} / \mathrm{L}\end{array}$ & $0.57 \pm 0.21$ & $0.66 \pm 0.09$ & $0.11(0.02-0.16)$ & $+21(15-29)$ & $\leq 0.001^{*}$ \\
\hline $\begin{array}{c}\text { Tot- } \mathrm{Mg}^{2+} \\
\mathrm{mmol} / \mathrm{L}\end{array}$ & $0.85 \pm 0.13$ & $1.06 \pm 0.13$ & $0.22(0.17-0.24)$ & $+27(21-33)$ & $\leq 0.001^{*}$ \\
\hline $\begin{array}{l}\text { Ion-Ca }{ }^{2+}, \\
\mathrm{mmol} / \mathrm{L}\end{array}$ & $1.13 \pm 0.09$ & $1.15 \pm 0.08$ & $0.01(-0.03$ to 0.05$)$ & $+1.5(-1$ to 4$)$ & 0.724 \\
\hline $\begin{array}{l}\mathrm{PO}_{4}^{3-} \\
\mathrm{mmol} / \mathrm{L}\end{array}$ & $1.49 \pm 0.46$ & $1.61 \pm 0.05$ & $0.08(-0.05$ to 0.30$)$ & $+11(2-20)$ & 0.532 \\
\hline $\begin{array}{l}\text { PTH, pmol/ } \\
\text { L }\end{array}$ & $\begin{array}{l}36.6 \\
\quad(28.8-51.9)\end{array}$ & $\begin{array}{l}34.4 \\
\quad(18.7-48.9)\end{array}$ & $-2.4(-8.5$ to 3.7$)$ & $-11(-22$ to 1$)$ & $0.034^{*}$ \\
\hline $\begin{array}{l}\text { 25-OH- } \\
\text { vitamin D, } \\
\mathrm{ng} / \mathrm{mL}\end{array}$ & $\begin{array}{l}34.8 \\
\quad(15.5-42.9)\end{array}$ & $\begin{array}{l}35.6 \\
\quad(29.5-40.2)\end{array}$ & $2.17(-3.7$ to 8.11$)$ & $+39(7-71)$ & $\leq 0.001^{*}$ \\
\hline
\end{tabular}

Baseline and follow-up values are described as mean \pm SD for variables with a normal distribution (total $\mathrm{Mg}$, ionized $\mathrm{Mg}$, ionized $\mathrm{Ca}$, and $\mathrm{PO}_{4}{ }^{3-}$ ) and as median and interquartile range for variables with a non-normal distribution ( $\mathrm{PTH}$ and $25-\mathrm{OH}$-vitamin D). Changes from baseline to follow-up are described as mean change with $95 \% \mathrm{CI}$ and as percentage of increase or decrease. Changes over time were analyzed using linear mixed models. As a result of skewed distributions, PTH and 25-OH-vitamin D were log-transformed in the models. We back-transformed the results to present the values, for ease of interpretation.. Baseline was defined as the mean of measurements on days -7 and 0 , and follow-up as the monthly or quarterly measurement mean after the end of the crossover

95\% CI 95\% confidence interval, Ion- $\mathrm{Mg}^{2+}$ ionized magnesium, $\mathrm{Tot}_{-} \mathrm{Mg}^{2+}$ total magnesium, Ion- $\mathrm{Ca}^{2+}$ ionized calcium; $\mathrm{PO}_{4}^{3-}$ phosphate, $\mathrm{PTH}$ intact parathyroid hormone

${ }^{*} p$ value $<0.05$

myocardial effect independent from changes in preload, afterload, heart rate, or flow [33].

Moreover, findings of a previous randomized controlled trial highlighted that in patients on $\mathrm{HD}$, increasing $\mathrm{D}-\mathrm{Mg}^{2+}$ concentration could prevent or reduce the incidence of IDH with important implications for dialysis tolerance [34]. It is important to note that even if a reduction in systolic blood pressure was found in our study, it did not correspond to a clinically significant increase in blood pressure-related events in patients exposed to higher $\mathrm{D}-\mathrm{Mg}^{2+}$ concentrations; hemodynamic effect which could partially explain the improvement in vascular stiffness observed in our study.

It should be noted that a previous randomized controlled study found that increasing
$\mathrm{D}-\mathrm{Mg}^{2+}$ decreases calcification propensity in subjects undergoing maintenance hemodialysis, which is another well-known determinant of arterial stiffness [11]. We can not exclude that the vascular improvement consequent to increasing D-Mg content in our trial could also be related to a decreased tendency to calcification, but we did not investigate this aspect.

Furthermore the vascular stiffness improvement found in our study was supported by a significant decrease of pulse pressure with the higher $\mathrm{D}-\mathrm{Mg}^{2+}$, which interrupts the "steep pressure-volume" vicious circle (increased pressure during ventricular ejection and decreased during diastolic runoff), which is one of the main determinants of large-artery stiffness $[35,36]$. The fact that low plasma 


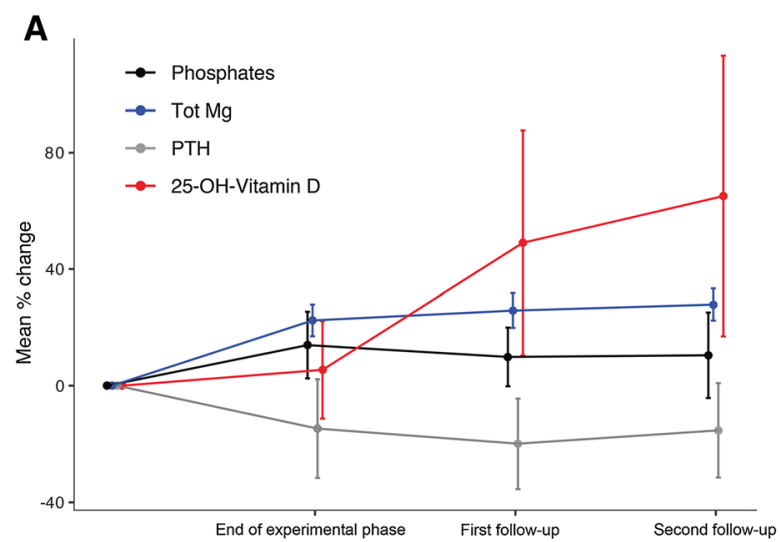

Fig. 4 Mean percentage change during the follow-up with high dialysate magnesium concentration $(0.75 \mathrm{mmol} / \mathrm{L})$ on selected markers of mineral and bone metabolism and on serum magnesium. Graphs represent quarterly percentage changes from baseline in total serum magnesium,

magnesium values are associated with high brachial pulse pressure as well as changes in aortic compliance related to loss of elastic material in smooth muscle cells was previously demonstrated [37, 38].

Our study also aimed to explore the effect of increasing $\mathrm{D}-\mathrm{Mg}^{2+}$ on endothelial functions expressed as RHI. Despite a trend suggesting an improvement, we were unable to show significant changes in that parameter during the $\mathrm{D}-\mathrm{Mg}^{2+} 0.75 \mathrm{mmol} / \mathrm{L}$ treatment $(+0.15$, CI $-0.35-0.65)$. It should be noted that even if endothelial dysfunction is a relevant topic in patients on HD, a very small number of previous studies have explored the reactivity of the endothelium using RHI as a parameter in these subjects [39]. The fact that most of these patients have an arteriovenous fistula potentially influencing the performance of the procedure could explain the small number of published studies exploring it.

We have to highlight that our study analyzed the effect of increasing the magnesium concentration in dialysate on whole blood ionized magnesium in patients on HD for the first time. This aspect is of clinical relevance, considering its ability, comparing with total serum magnesium, to unmask hypo- and hypermagnesemia. In line with previous trials, increasing $\mathrm{D}-\mathrm{Mg}^{2+}$ concentration was
B

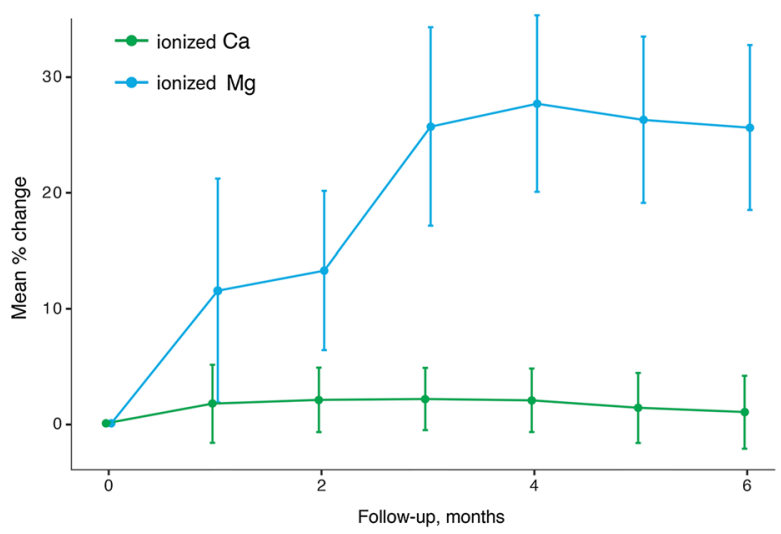

phosphate, intact parathyroid hormone (PTH), and 25-OH-vitamin D (a) and monthly percentage change in ionized calcium and ionized magnesium (b). Error bars in all panels represent $95 \%$ confidence intervals

associated with a significant increase in serum tot-Mg and whole blood ion-Mg, but does not affect whole blood ionized calcium.

Previous studies have found a good correlation between total and ionized magnesium in both healthy and unhealthy populations [27]. However, currently, there is no established threshold for defining optimal ionized $\mathrm{Mg}$, and reference values based on predictions of health outcome are lacking. The chosen range of normality was based on a previous study performed in our dialysis network using the same assay [40].

Total magnesium levels are significantly influenced by serum albumin concentration, with an increasing risk of overestimating the incidence of hypomagnesemia when hypoalbuminemia is present [41]. Thus it is reasonable to affirm that the determination of total magnesium is reflective of ionized magnesium concentration under normoproteinemia conditions and that the evaluation of ionized magnesium could be clinically relevant if hypomagnesemia is suspected and/or hypoalbuminemia is present [42]. Nevertheless, no episodes of severe and/or symptomatic hypermagnesemia occurred, in both the interventional and follow-up phases. In any case, we believe it would be prudent to monitor serum $\mathrm{Mg}$ in clinical practice, considering the risk of progressive expansion of the 
magnesium pool using higher $\mathrm{D}-\mathrm{Mg}^{2+}$ concentrations.

As observed during the crossover, increasing the D-Mg ${ }^{2+}$ concentration could possibly lead to a benefit in terms of arterial stiffness in the absence of significant hemodynamic adverse events and of unfavorable consequences on bone metabolism during the follow-up. However, in our cohort, the mean baseline serum magnesium level was relatively low $(0.84 \mathrm{mmol} / \mathrm{L}) \quad$ comparing with other hemodialysis cohorts previously investigated [18]. This aspect could be related to the older age of our population, with a mean age of 77 years. It is therefore possible to speculate that the safety of increasing $\mathrm{D}-\mathrm{Mg}^{2+}$ in our population was partially due to the relatively low $\mathrm{Mg}$ levels at baseline. We cannot exclude that these findings might not be reliable for younger cohorts with higher serum Mg levels.

Moreover, on the basis of the present findings, it is not possible to affirm that increasing the $\mathrm{D}-\mathrm{Mg}^{2+}$ to higher concentrations (e.g., $1 \mathrm{mmol} / \mathrm{L}$ or higher) would produce the same benefits in the absence of adverse events.

Considering the high intra-individual variability of serum magnesium (largely multifactorial and dependent in particular on age, nutritional habits, food intake and supplements, and drugs), the best option in patients on HD would be the personalization of the HD treatment, individualizing the concentrations of magnesium in the dialysate. However, currently, the optimal $\mathrm{D}-\mathrm{Mg}^{2+}$ concentration and the best strategy to tailor the dialysate both remain unknown. Determining the intraindividual variability of serum magnesium could support the choice of the $\mathrm{D}-\mathrm{Mg}^{2+}$ concentration, allowing one to detect patients at higher risk of hyper- and hypomagnesemia and avoiding both extraskeletal calcifications and the risk of adynamic bone disease.

During the follow-up phase, in which patients were treated with high $\mathrm{D}-\mathrm{Mg}^{2+}, \mathrm{a}$ decreasing PTH level was observed. It is important to note that the metabolism of magnesium and calcium are closely interrelated and that our observation is in line with previous experimental in vivo and in vitro findings $[43,44]$. Even if the exact mechanism is still not clear, this could be the consequence of a calcimimetic effect of $\mathrm{Mg}$, stimulating the Ca-sensing receptor of the parathyroid glands in a way similar to calcium [33]. Furthermore, considering the hemodynamic consequences of changing the magnesium concentration in dialysate, the intrinsic role of magnesium in calcium channel function, increasing the production of nitric oxide and vasodilator molecules (i.e., prostacyclins), and modulating the effect of vasoactive agents also has to be highlighted $[45,46]$.

The present study includes some points of strength such as its crossover design, the randomization, and the long-term follow-up. Moreover in this study, a higher incidence of adverse events in the $\mathrm{D}-\mathrm{Mg}^{2+} 0.75 \mathrm{mmol} / \mathrm{L}$ compared with the $\mathrm{D}-\mathrm{Mg}^{2+} 0.50 \mathrm{mmol} / \mathrm{L}$ treatment group was not found. However, it is important to note that the hemodynamic events considered as adverse events in the present study are not Mg-specific, and could be related to other HD intercurrent conditions. In any case the absence of significant differences in adverse events between treatment groups allows us to postpone a cause-effect speculation. Finally, we have to acknowledge that considering the relatively small size of the study cohort and the short duration of the crossover phases, it was not possible to rule out rare or long-term complications.

We also have to acknowledge some further limitations: the single-center design, the relatively small number of participants, and the related limited statistical power to demonstrate benefits in endothelial functions, the short duration of each treatment phase, which may not have been sufficient for the best estimate of the benefits in terms of arterial stiffness and endothelial functions, and the absence of hemodynamic and endothelial function monitoring in the follow-up phase. The open-label study design during the crossover phase and the absence of a control group during the long-term follow-up of the study represent other important limitations of our study. Moreover, in our cohort, the mean baseline serum magnesium level was relatively low $(0.84 \mathrm{mmol} / \mathrm{L})$ comparing with other hemodialysis cohorts previously investigated [18]. This aspect could be related to the older age of our population, with a mean 
age of 77 years. It is therefore possible to speculate that the safety of increasing $\mathrm{D}-\mathrm{Mg}^{2+}$ in our population was partially due to the relatively low $\mathrm{Mg}$ levels at baseline. We cannot exclude that these findings might not be reliable for younger cohorts with higher serum Mg levels.

We also have to acknowledge that PWV exhibits a certain degree of variability during HD consequent to BP, solute concentration, and volume status changes [47]. In any case, in the present study no difference in ultrafiltered volume between treatment groups was detected. Furthermore, it is important to note that studies exploring the effect of fluid status on arterial stiffness have shown contrasting results and that recent findings have suggested that the major determinant of PWV in HD could be the arterial wall damage rather than hydration status and BP [48].

It was also demonstrated that volume status and overload, independently from BP, were associated with carotid-femoral (central), but not with carotid-brachial (peripheral) PWV, in patients on HD [49].

In the present study, the absence of a washout completing the crossover design is a limitation. A washout phase longer than the usual 3 days of intradialytic stop was, however, not performed on the basis of two considerations: (i) a washout including HD sessions, and using one of the two $\mathrm{D}-\mathrm{Mg}^{2+}$ concentrations tested, would have resulted in a prolongation of one of the two treatment modalities under investigation; and (ii) in the worst case of a carryover effect, the magnitude of the artery wall response and hemodynamic changes would have been reduced. Being aware that it is not possible to "washout" the magnesium and come back to the baseline value without the clearing effect of the hemodialysis treatment, the absence of a significant carryover or period effect was formally tested and confirmed for all outcomes. Furthermore, measurements obtained during the $\mathrm{D}-\mathrm{Mg}^{2+} 0.50 \mathrm{mmol} / \mathrm{L}$ treatment, as well as during the $\mathrm{D}-\mathrm{Mg}^{2+} 0.75 \mathrm{mmol} / \mathrm{L}$ treatment, were pooled, and analyses were carried out ignoring the treatment order. We are, however, aware that even if we can deny any carryover effect from a statistical perspective, we cannot with certainty assume that all parameters returned to pre-treatment levels.

Last but not least, the primary outcomes investigated, even if recognized as independent $\mathrm{CV}$ risk factors, are surrogate indicators of CVD. In any case the study was not designed to assess whether improvement in arterial stiffness and hemodynamics was associated with a reduction in the incidence of cardiovascular events or mortality.

Despite all the aforementioned limitations, this is the first randomized crossover study which assesses the effect of high $\mathrm{D}-\mathrm{Mg}^{2+}$ concentration on hemodynamics, arterial stiffness, and endothelial functions in patients with ESRD. A larger trial may be necessary to evaluate the effects of a $0.75 \mathrm{mmol} / \mathrm{L} \mathrm{D}-\mathrm{Mg}^{2+}$ on major clinical outcomes in patients with ESRD.

\section{CONCLUSIONS}

Increasing magnesium in dialysate represents an easy, effective therapeutic option in patients undergoing hemodialysis to increase serum magnesium which could promote cardiovascular benefits. In this trial we found that $\mathrm{D}-\mathrm{Mg}^{2+}$ at $0.75 \mathrm{mmol} / \mathrm{L}$ improves vascular stiffness in subjects undergoing maintenance hemodialysis. The present findings merit a larger trial to evaluate the effects of increasing magnesium in dialysate on major clinical outcomes.

\section{ACKNOWLEDGEMENTS}

We would like to thank the study participants for their valuable contribution. We would like also to thank all the study nurses of the Dialysis Center for their support in the data collection, Ms. Irene Menghini and her staff for data entry, and Salvatore Assenzio for the graphic art assistance.

Funding. We gratefully acknowledge the financial support of the Scientific Research Advisory Board (ABREOC) of the Ente Ospedaliero Cantonale, Bellinzona, Switzerland. The funding source had no role in study design, data 
collection, data analysis, data interpretation, or writing of the report. The Rapid Service and Open Access Fees was funded by the Scientific Research Fund of the Internal Medicine Department of the Ospedale San Giovanni, Bellinzona, Switzerland.

Authorship. All named authors meet the International Committee of Medical Journal Editors (ICMJE) criteria for authorship for this article, take responsibility for the integrity of the work as a whole, and have given their approval for this version to be published.

Authorship Contributions. Rosaria Del Giorno and Soraya Lavorato Hadjeres equally contributed to this work. All named authors meet the International Committee of Medical Journal Editors (ICMJE) criteria for authorship for this article, take responsibility for the integrity of the work as a whole, and have given their approval for this version to be published.

Prior Presentation. This work has been previously presented as an abstract at the Virtual Congress 2020 of the European Renal Association-European Dialysis and Transplant Association (ERA-EDTA), 6-9 June 2020.

Disclosures. Rosaria Del Giorno, Soraya Lavorato Hadjeres, Kevyn Stefanelli, Giampiero Allegra, Claudia Zapparoli, Lazarevic Predrag, Lorenzo Berwert, and Luca Gabutti have nothing to disclose.

Compliance with Ethics Guidelines. The study adhered to the principles of the Declaration of Helsinki and was approved by the Swiss Ethics Commission (comitato etico canton Ticino, ID number CE 3358, 2018). All study participants gave written informed consent. All procedures performed in studies involving human participants were in accordance with the ethical standards and with the 1964 Helsinki declaration and its later amendments or comparable ethical standards. The study was retrospectively registered on the ISRCTN registry (ISRCTN 74139255) on June 18, 2020. All participants signed an informed consent document.
Data Availability. The datasets generated during the current study are not expected to be made publicly available as participant consent forms and ethics approval did not include permission for secondary use, with access to data only approved for researchers involved in the analysis.

Open Access. This article is licensed under a Creative Commons Attribution-NonCommercial 4.0 International License, which permits any non-commercial use, sharing, adaptation, distribution and reproduction in any medium or format, as long as you give appropriate credit to the original author(s) and the source, provide a link to the Creative Commons licence, and indicate if changes were made. The images or other third party material in this article are included in the article's Creative Commons licence, unless indicated otherwise in a credit line to the material. If material is not included in the article's Creative Commons licence and your intended use is not permitted by statutory regulation or exceeds the permitted use, you will need to obtain permission directly from the copyright holder. To view a copy of this licence, visit http://creativecommons.org/licenses/by$\mathrm{nc} / 4.0 /$.

\section{REFERENCES}

1. Bhatti NK, Karimi Galougahi K, et al. Diagnosis and management of cardiovascular disease in advanced and end-stage renal disease. J Am Heart Assoc. 2016;5(8):e003648.

2. Jablonski KL, Chonchol M. Vascular calcification in end-stage renal disease. Hemodial Int. 2013. https://doi.org/10.1111/hdi.12084.

3. Cozzolino M, Mangano M, Stucchi A, et al. Cardiovascular disease in dialysis patients. Nephrol Dial Transplant. 2018;33(Suppl_3):28-34.

4. Zanoli L, Lentini P, Briet M, et al. Arterial stiffness in the heart disease of CKD. J Am Soc Nephrol. 2019;30(6):918-28.

5. Gorgulu N, Yelken B, Caliskan Y, et al. Endothelial dysfunction in hemodialysis patients with failed renal transplants. Clin Transplant. 2010;24(5): 678-84. 
6. Ter Braake AD, Shanahan CM, de Baaij JHF. Magnesium counteracts vascular calcification: passive interference or active modulation? Arterioscler Thromb Vasc Biol. 2017;37(8):1431-45.

7. Ter Braake AD, Tinnemans PT, et al. Magnesium prevents vascular calcification in vitro by inhibition of hydroxyapatite crystal formation. Sci Rep. 2018;8:2069.

8. Floege J. Magnesium in CKD: more than a calcification inhibitor? J Nephrol. 2015;28(3):269-77.

9. Bressendorff I, Hansen D, Pasch A, et al. The effect of increasing dialysate magnesium on calciprotein particles, inflammation and bone markers: post hoc analysis from a randomized controlled clinical trial. Nephrol Dial Transplant. 2019. https://doi.org/10. 1093/ndt/gfz234.

10. Sakaguchi Y, Fujii N, Shoji T, et al. Hypomagnesemia is a significant predictor of cardiovascular and non-cardiovascular mortality in patients undergoing hemodialysis. Kidney Int. 2014;85(1): 174-81.

11. Sakaguchi Y, Hamano T, Obi Y, et al. A randomized trial of magnesium oxide and oral carbon adsorbent for coronary artery calcification in predialysis CKD. J Am Soc Nephrol. 2019;30(6):1073-85.

12. Pérez-García R, Jaldo MT, Puerta M, et al. Hypomagnesaemia in haemodialysis is associated with increased mortality risk: its relationship with dialysis fluid. Nefrologia. 2020;S0211-6995(20): 30072-82.

13. Saver JL, Starkman S, Eckstein M, et al. Prehospital use of magnesium sulfate as neuroprotection in acute stroke. N Engl J Med. 2015;372(6):528-36.

14. Kostov K, Halacheva L. Role of magnesium deficiency in promoting atherosclerosis, endothelial dysfunction, and arterial stiffening as risk factors for hypertension. Int J Mol Sci. 2018;19(6):E1724.

15. Maier JA, Malpuech-Brugère $C$, et al. Low magnesium promotes endothelial cell dysfunction: implications for atherosclerosis, inflammation and thrombosis. Biochim Biophys Acta. 2004;1689(1): 13-211.

16. Ter Braake AD, Eelderink C, Zeper LW, et al. Calciprotein particle inhibition explains magnesiummediated protection against vascular calcification. Nephrol Dial Transplant. 2020;35(5):765-73.

17. Del Giorno R, Riva H, Donato G, et al. Ionized and total serum magnesium in hemodialysis: predictors and variability. A longitudinal cross-sectional study. Clin Exp Nephrol. 2018;22(3):620-8.
18. Bressendorff I, Hansen D, Schou M, et al. The effect of increasing dialysate magnesium on serum calcification propensity in subjects with end stage kidney disease: a randomized, controlled clinical trial. Clin J Am Soc Nephrol. 2018;13(9):1373-80.

19. Jefferies HJ, Lemoine S, McIntyre CW. High magnesium dialysate does not improve intradialytic hemodynamics or abrogate myocardial stunning. Hemodial Int. 2020. https://doi.org/10.1111/hdi. 12863.

20. Kooman J, Basci A, Pizzarelli F, et al. EBPG guideline on haemodynamic instability. Nephrol Dial Transplant. 2007;22(Suppl 2):2-44.

21. K/DOQI Workgroup. K/DOQI clinical practice guidelines for cardiovascular disease in dialysis patients. Am J Kidney Dis. 2005;45(4Suppl 3): S1-153.

22. Wei W, Tölle M, Zidek W, et al. Validation of the mobil-O-Graph: $24 \mathrm{~h}$-blood pressure measurement device. Blood Press Monit. 2010;15(4):225-58.

23. Wassertheurer S, Kropf J, Weber T, et al. A new oscillometric method for pulse wave analysis: comparison with a common tonometric method. J Hum Hypertens. 2010;24(8):498-504.

24. Hametner B, Wassertheurer S, Kropf J, Mayer C, Eber B, Weber T. Oscillometric estimation of aortic pulse wave velocity: comparison with intra-aortic catheter measurements. Blood Press Monit. 2013;18(3):173-6.

25. Sarafidis PA, Georgianos PI, Karpetas A, et al. Evaluation of a novel brachial cuff-based oscillometric method for estimating central systolic pressure in hemodialysis patients. Am J Nephrol. 2014;40(3): 242-50.

26. Weiss W, Gohlisch C, Harsch-Gladisch C, Tölle M, Zidek W, van der Giet M. Oscillometric estimation of central blood pressure: validation of the MobilO-Graph in comparison with the SphygmoCor device. Blood Press Monit. 2012;17(3):128-31.

27. Liu W, Meng M, Chen J, et al. Reactive hyperemia index in patients on maintenance hemodialysis: cross-sectional data from a cohort study. Sci Rep. 2017;7:45757.

28. Cohn JN, Quyyumi AA, Hollenberg NK, et al. Surrogate markers for cardiovascular disease: functional markers. Circulation. 2004;109:31-46.

29. Joris PJ, Plat J, Bakker SJ, et al. Long-term magnesium supplementation improves arterial stiffness in overweight and obese adults: results of a randomized, double-blind, placebo-controlled intervention trial. Am J Clin Nutr. 2016;103(5):1260-6. 
30. Sakaguchi Y, Hamano T, Isaka Y. Magnesium and progression of chronic kidney disease: benefits beyond cardiovascular protection? Adv Chronic Kidney Dis. 2018;25(3):274-80. https://doi.org/10. 1053/j.ackd.2017.11.001.

31. Lioufas N, Hawley CM, Cameron JD, et al. Chronic kidney disease and pulse wave velocity: a narrative review. Int J Hypertens. 2019;2019:9189362.

32. Adenwalla SF, Graham-Brown MPM, Leone FMT, et al. The importance of accurate measurement of aortic stiffness in patients with chronic kidneydisease and end-stage renal disease. Clin Kidney J. 2017;10(4):503-15.

33. Shanahan CM. Mechanisms of vascular calcification in CKD-evidence for premature ageing? Nat Rev Nephrol. 2013;9(11):661-70.

34. Kostov K, Halacheva L. Role of magnesium deficiency in promoting atherosclerosis, endothelial dysfunction, and arterial stiffening as risk factors for hypertension. Int J Mol Sci. 2018;19(6):1724.

35. Kyriazis J, Kalogeropoulou K, Bilirakis L, et al. Dialysate magnesium level and blood pressure. Kidney Int. 2004;66(3):1221-31.

36. Said MA, Eppinga RN, Lipsic E, et al. Relationship of arterial stiffness index and pulse pressure with cardiovascular disease and mortality. J Am Heart Assoc. 2018;7(2):e007621.

37. Boutouyrie P, Fliser D, Goldsmith D, et al. Assessment of arterial stiffness for clinical and epidemiological studies: methodological considerations for validation and entry into the European Renal and Cardiovascular Medicine registry. Nephrol Dial Transplant. 2014;29(2):232-9.

38. Laurent S, Boutouyrie P, Lacolley P. Structural and genetic bases of arterial stiffness. Hypertension. 2005;45:1050-5.

39. Afsar B, Elsurer R. The relationship between magnesium and ambulatory blood pressure, augmentation index, pulse wave velocity, total peripheral resistance, and cardiac output in essential hypertensive patients. J Am Soc Hypertens. 2014;8(1): 28-35.
40. DiNicolantonio JJ, O'Keefe JH, Wilson W. Subclinical magnesium deficiency: a principal driver of cardiovascular disease and a public health crisis. Open Heart. 2018;5(1):e000668.

41. Terink R, Balvers MG, Bongers CCWG, et al. Ionized and total magnesium levels change during repeated exercise in older adults. J Nutr Health Aging. 2019;23(6):595-601.

42. Costello RB, Nielsen F. Interpreting magnesium status to enhance clinical care: key indicators. Curr Opin Clin Nutr Metab Care. 2017;20:504-11.

43. Navarro JF, Mora C, Jiménez A, et al. Relationship between serum magnesium and parathyroid hormone levels in hemodialysis patients. Am J Kidney Dis. 1999;34(1):43-8.

44. Paunier L. Effect of magnesium on phosphorus and calcium metabolism. Monatsschr Kinderheilkd. 1992;140(9 Suppl 1):S17-20.

45. Das UN. Delta 6 desaturase as the target of the beneficial actions of magnesium. Med Sci Monit. 2010;16:LE11-12.

46. Rodríguez-Ortiz ME, Canalejo A, Herencia C, et al. Magnesium modulates parathyroid hormone secretion and upregulates parathyroid receptor expression at moderately low calcium concentration. Nephrol Dial Transplant. 2014;29(2):282-9.

47. Tycho Vuurmans JL, Boer WH, Bos WJ, Blankestijn PJ, Koomans HA. Contribution of volume overload and angiotensin II to the increased pulse wave velocity of hemodialysis patients. J Am Soc Nephrol. 2002;13(1):177-83.

48. Bia D, Galli C, Valtuille R, et al. Hydration status is associated with aortic stiffness, but not with peripheral arterial stiffness, in chronically hemodialysed patients. Int J Nephrol. 2015;2015: 628654. https://doi.org/10.1155/2015/628654.

49. Di Iorio B, Nazzaro P, Cucciniello E, Bellizzi V. Influence of haemodialysis on variability of pulse wave velocity in chronic haemodialysis patients. Nephrol Dial Transplant. 2010;25(5):1579-83. 